\title{
Methods of deconditioning persisting avoidance: Amphetamine, chlorpromazine, and chlordiazepoxide as adjuncts to response prevention*
}

\author{
SIDNEY COOPER, KATHLEEN COON, CHERYL MEJTA, aid LARRY REID \\ Bradley University, Peoria, Illinois 61606
}

\begin{abstract}
Rats were given extended avoidance training in an automated one-way avoidance chamber, a chamber with a retractable ledge. After training and footshock termination, some rats were prevented from responding by being trapped on the footshock grid with the ledge removed. During this response prevention, rats were under the influence of either amphetamine, chlorpromazine, culordiazejoxide, or a placebo. Subsequently, rats were tested for continuance of responding when footshock no longer occurred. Only response prevention with amphetamine reduced persisting avoidance responding compared to no treatment.
\end{abstract}

Systematic desensitization and implosion therapy are two laboratory-based therapies that have emerged as alternatives to traditional psychotherapy (Wolpe, 1958; Stampfl \& Levis, 1968). Implosion therapy is a response-prevention (RP) procedure. Systematic desensitization also incorporates a form of RP in that the procedure arranges for periodic confrontation with fear-eliciting stimuli. In the animal laboratory, RP is typically arranged by physically blocking the Ss' avoidance responses. Thus implosion therapy, systematic desensitization therapy, and RP procedures as used in the animal laboratory have similar cnaracteristics and resemble forced reality testing (Baum, 1970), a component of many traditional psychotherapies.

Drugs have been used to facilitate deconditioning of persisting avoidance. Brady (1966), Friedman (1966), and Kraft (1967) reported that short-acting barbiturates, when used with desensitization therapy, helped remediate a variety of human phobias. Attempts, however, to facilitate RP using "relaxing" or "tranquilizing" drugs with laboratory animals have produced equivocal results (Nelson, 1967; Kamano, 1968; Baum, 1973), necessitating furtner research. This study was a test of three different drugs in rats with well-established avoidance. The metnods were similar to those described by Baum $(1965,1973)$, except that many more avoidance trials were given prior to introduction of drugs and RP.

\section{METHOD}

\section{Subjects}

Prior to training, 48 adult male Sprague-Dawley rats were housed in $60 \times 45 \times 68 \mathrm{~cm}$ cages, 12 rats per cage. After completion of the first training session, a rat was placed in a

\footnotetext{
*This study was supported by Bradley University's Board for Research and Grant DA01049 from the National Institute of Drug Abuse. We thank Cynthia A. Royer for help in testing the rats.
}

small cage $(24 \times 18 \times 18 \mathrm{~cm})$, where it was maintained for the duration of the experiment. On the first day of training, rats were experimentally naive, 150-174 days of age, and weighed $300-470 \mathrm{~g}$.

\section{Apparatus}

The automated apparatus was a Plexiglas box $(30 \times 30 \times$ $39 \mathrm{~cm}$ ) fitted with an electrifiable grid floor and a retractable ledge ( $30 \mathrm{~cm}$ wide). The ledge was $14 \mathrm{~cm}$ above the grid floor and, when not retracted, projected $7 \mathrm{~cm}$ into the chamber. Shock intensity was always $1.3 \mathrm{~mA}$ and was generated by a Grason-Stadler shock source and scrambler. Rat's presence on the ledge was detected by a photocell system.

\section{Procedure}

At the start of training, a rat was placed directly on the grid floor. After $10 \mathrm{sec}$, the grid became electrified and $\mathrm{S}$ received footshock until it escaped to the ledge. $S$ was permitted to remain on the ledge for $30 \mathrm{sec}$ after which the ledge retracted, returning the rat to the grid, and initiating the next trial. $S$ could avoid shock by climbing to the ledge within $10 \mathrm{sec}$ after ledge return. If $\mathrm{S}$ left the ledge before $30 \mathrm{sec}$ elapsed, a rare event, the ledge retracted and returned and a new trial began.

All Ss received 700 training trials, 100 trials on each of 7 consecu tive days. To ensure that Ss received an equally recent experience of footshock prior to treatment, all were subjected to unavoidable but escapable shock (about $1 \mathrm{sec}$ ) on the 690th trial.

On the 8th consecutive day, $\mathrm{S}$ was given an intraperitoneal injection of either d-amphetamine sulfate (AMPH) $(2 \mathrm{mg} / \mathrm{kg})$, chlorpromazine (CPZ) $(2 \mathrm{mg} / \mathrm{kg})$, or sterile water. Volume of all injections equalled $0.2 \mathrm{ml}$. Following injection, $\mathrm{S}$ was either placed directly on the grid fllor of the apparatus, with the ledge retracted and shocker disconnected, where it remained for $60 \mathrm{~min}(\mathrm{RP})$ or was placed in a metal pail beside the apparatus for $60 \mathrm{~min}$ (no RP). Then $\mathrm{S}$ was returned to its home cage where it remained for 5 days to assure metabolism of drugs prior to posttreatment testing.

On the 13th day after the start of training, $\mathrm{S}$ was returned to the avoidance chamber and testing under conditions of extinction was begun. Extinction trials were similar to training trials except that shock no longer occurred, although the sounds of the shock scrambler continued as during training. $S$ met criterion when it remained on the grid floor for 5 consecutive min.

Twenty-two days later, three Ss were randomly selected from 
Table 1

Treatments and Outcomes

\begin{tabular}{|c|c|c|c|c|c|c|}
\hline \multirow[b]{2}{*}{ Response Prevention (Min) } & \multicolumn{2}{|c|}{$\mathrm{CPZ}$} & \multicolumn{2}{|c|}{$\begin{array}{c}\text { Drug Treatments } \\
\text { Placebo }\end{array}$} & \multicolumn{2}{|c|}{ AMPH } \\
\hline & 60 & 0 & 60 & 0 & 60 & 0 \\
\hline & \multicolumn{6}{|c|}{ Trials to Criterion } \\
\hline Mean & 274.6 & 306.4 & 121.4 & 415.6 & 14.8 & 250.8 \\
\hline Median & 6.5 & 191 & 9.0 & 318 & 0.9 & 174 \\
\hline Highest & 690 & 1015 & 392 & 1014 & 98 & 702 \\
\hline Lowest & 0 & 0 & 0 & 0 & 0 & 0 \\
\hline $\mathrm{S} / \mathrm{n}$ at $<10 \mathrm{Rs}$ & $4 / 8$ & $3 / 8$ & $4 / 8$ & $1 / 8$ & $6 / 8$ & $2 / 8$ \\
\hline
\end{tabular}

Note-S/n at $<10$ Rs is number of subjects per group which made fewer than 10 responses to reach extinction criterion.

each of the six original groups for further testing. These eighteen Ss were assigned to one of three groups, six Ss per group, such that each of the original groups was equally represented. Ss received an additional 200 training trials, 100 trials on each of 2 consecutive days, and were subjected to $1 \mathrm{sec}$ of inescapable footshock on the 190th trial.

On the next day, $\mathrm{S}$ was given an intraperitoneal injection of either $5 \mathrm{mg} / \mathrm{kg}$ chlordiazepoxide (CDP), $20 \mathrm{mg} / \mathrm{kg}$ CDP (clinically low and medium doses, respectively, Heise \& Boff, 1962), or sterile water. All injections were $1 \mathrm{cc} / \mathrm{kg}$. Immediately after injection, $S$ was returned to its home cage for $30 \mathrm{~min}$ to allow the drug to take effect. All Ss were then given $30 \mathrm{~min}$ RP.

The posttreatment test, without footshock, of course, was begun $24 \mathrm{~h}$ after drug injection, a time sufficient for CDP to metabolize (Richelle, Xhenseval, Fontaine, \& Thone, 1970). Testing continued until $S$ reached a criterion of 5 consecutive minutes on the grid without responding.

\section{RESULTS}

To assure that posttreatment differences in the first test, if any, were the result of treatment and not pretreatment differences among Ss, pretreatment measures (latency of first response, average latency of first responses on last 6 days of training, and total number of escapes throughout training) were analyzed with data grouped according to Ss' eventual treatments. The statistic used was the one used to analyze posttreatment measures (a Mann-Whitney U between the groups scoring at opposite extremes on each of the measures). The result (all $\mathrm{p}$ values $>.1$ ) suggested that there is no basis for concluding that groups differed reliably prior to treatment.

Kendall's coefficient of concordance, W, of the four posttreatment measures (trials, "avoidances," and "escapes" to criterion, and latency of of first response) equalled .83 , indicating a high degree of agreement among the posttreatment measures. Therefore, analyses of only one of them, trials to criterion, are presented. Data of trials to criterion are presented in Table 1.

The data were analyzed using Ryan's method for making multiple comparisons among samples. "Ryan's procedure provides an alternative to the Kruskal-Wallis overall null hypothesis test [Kirk, 1968, p. 496]." The method involves using the Mann-Whitney $U$ test and adjusting the alpha level for step-wise comparisons. The
Mann-Whitney $U$ for the comparison of the two extreme outcomes (no RP with sterile water vs RP with AMPH) yielded a $U$ of $6.5, p=.0025$. With Ryan's method, the adjusted alpha level for the extreme comparison is .0033 to meet the standard of $p<.05$. Since the achieved $p$ value is less than Ryan's standard, it can be concluded that the AMPH with response-prevention treatment differed reliably from no treatment. Other comparisons did not meet the standard for a reliable difference.

Kruskal-Wallis ANOVAs were computed on the following pretreatment measures in the second test: latency of first response and total number of escapes made throughout training, with data grouped according to Ss' eventual treatments. These analyses indicated that there was no basis for concluding that the groups differed reliably prior to treatment (corrected for ties, $\mathrm{H}=.6, \mathrm{p}>.70$, for latency of first response; corrected for ties, $\mathrm{H}=4.4, \mathrm{p}>.10$, for total escapes; both $\mathrm{df}=2$ ).

Summary of posttreatment data of the second test appears in Table 2. Again, using Ryan's method, a Mann-Whitney $U$ test was done on the extreme values for trials to criterion (treatments of $0 \mathrm{mg} / \mathrm{kg}$ and $5 \mathrm{mg} / \mathrm{kg} \mathrm{CDP}$ ). This comparison did not meet the standard of reliability of differences $(U=18, p=.531)$.

Table 2

Treatments and Outcomes

\begin{tabular}{lccc}
\hline & \multicolumn{3}{c}{ Treatments } \\
CDP Dose (mg/kg) & 0 & 5 & 20 \\
Response Prevention (Min) & 30 & 30 & 30 \\
& \multicolumn{3}{c}{ Trials to Criterion } \\
Mean & $428.8+$ & 277.7 & 371.0 \\
Median & $366.0+$ & 216.0 & 363.5 \\
Highest & $1065+$ & 477 & 650 \\
Lowest & 1 & 91 & 99 \\
S/n at $<10 \mathrm{Rs}$ & $3 / 6$ & $0 / 6$ & $0 / 6$ \\
\hline
\end{tabular}

Note-During extinction for one subject, the equipment malfunctioned on the 1065 th trial, leaving the ledge retracted out of the chamber for approximately $2 \mathrm{~h}$. After the apparatus was repaired, the subject remained on the grid and made no additional responses. It can be safely assumed, however, that had the apparatus continued to function properly, the subject would have continued responding beyond the 1065th trial-thus, the plus sign after this, the highest score, and the mean and median scores. 


\section{DISCUSSION}

Kamano (1972) reported that CDP with response prevention enhanced persisting avoidance. Even though we found no differences among groups in our second test, our data do not contradict Kamano's data. The fact that our groups were small and their witnin-group variances were large may have led to the conclusion that there were no reliable differences between groups when, in fact, differences existed. In addition, the fact that Ss received extensive training (a total of 900 training trials) may have overshadowed any potential enhancement effect of the drug. It is therefore inappropriate to conclude that CDP has no effect, but it is evident from these and Kamano's data that CDP is not a reasonable adjunct to response prevention. The results of the first test and the results of Baum (1973) indicate that CPZ also is not an efficient adjunct to response prevention. Apparently, the "antianxiety" and "tranquilizing" drugs can either facilitate subsequent responding or produce little or no effect.

AMPH did facilitate the processes of response prevention. This result seems to get at a controversial issue. Stampfl and Levis (1968) have suggested that maximum fear elicitation is necessary for successful implosion therapy (a response-prevention procedure) and consequently it follows that a drug which reduces fear would reduce the effectiveness of the response prevention. Kamano's (1972) data with CDP and data with CDP and CPZ from both tests of this experiment support that proposition. Additionally, Hogan (undated mimeo ${ }^{1}$ ) said, "it seems reasonable to assume that drugs could heighten the experience of anxiety and aid in extinction procedures [p. 3]." Baum (1973) apparently disagrees. Although the rats in his study receiving CPZ during response prevention did not respond reliably less in extinction, he reported a nonsignificant trend in that rirection and also noted that those animals behaved less fearfully during response prevention. Thus, he concluded "all that is required is that the animal confront the feared situation during flooding, and if the stressfulness or amount of fear evoked by the experience is minimized, then the efficacy of flooding is not diminished and may even be enhanced [Baum, 1973, p. 4].” Although AMPH may not induce anxiety, it is surely an agent that produces something other than "relaxation." Consequently, our data seem to be more in agreement with the ideas of Stampfl, Levis, and Hogan. It seems that fear needs to be present for the fear to be efficiently extinguished or counterconditioned, and once fear is reduced, then the rats will be "relaxed." It may not be possible to by-pass the fear elicitation and go straight to "relaxation" and expect, on a subsequent occasion, to see diminished fear.

When intracranial stimulation of the lateral hypothalamus, which serves as a potent counterconditioner, is used as an adjunct to response prevention in animal studies, the stimulation is usually delivered in short trains interspersed througnout response prevention. In the human studies where short-acting barbiturates were used successfully as counterconditioners in systematic desensitization, small doses were delivered periodically througiout deconditioning via an intravenous cannula (Brady, 1966; Friedman, 1966; Kraft, 1967). What appears to be the salient characteristic of successful treatments is rapid alternation between fear and the state elicited by the counterconditioner (e.g., ICS-"pleasure," relaxation, or drug state). It may be that the chronic state of "tranquilization" produced by drugs such as CDP and CPZ, does not allow for rapid alternation of fear confrontation and fear inhibition which seems to be essential for effective fear reduction.

There is another explanation of why potentially fear-inhibiting drugs do not facilitate response prevention. Kamano (1972) suggested a state-specific learning explanation, i.e., the drug, by dissociating learning from the nondrugged state, did not allow transfer of training. The paradigm used to test for "therapeutic" effects of drugs is the same as the paradigm for testing for state-specific learning or transfer of training. Whether one wants to call the effect "lack of transfer," "state-specific learning," or "no fear, hence no fear extinction" seems moot from a simple practical point of view. Regardless of the exact process, some tranquilizing and antianxiety drugs do not reduce persisting avoidance and may even enhance it.

One further comment. Intracranial stimulation of the lateral hypothalamus is a remarkably efficient counterconditioner of persisting avoidance (Gordon \& Baum, 1971). AMPH facilitates pressing for ICS and CPZ does the opposite. Interestingly, AMPH and ICS both increase cerebral norepinephrine and $\mathrm{CPZ}$ reduces effective norepinephrine (Stein, 1964).

\section{REFERENCES}

Baum, M. An automated apparatus for the avoidance training of rats. Psychological R eports, 1965, 16, 1205-1212.

Baum, M. Extinction of avoidance responding through response prevention (flooding). Psychological Bulletin, 1970, 74, 276-284.

Baum, $M$. Extinction of avoidance in rats: The effects of chlorpormazine and methylphenidate administered in conjunction with flooding (response prevention). Behavior Research \& Therapy, 1973, 11, 1-5.

Brady, J. P. Brevital-relaxation treatment of frigidity. Behavior R esearch \& Therapy, 1966, 4, 71-77. Friedman, D. Treatment of a case of dog phobia in a deaf mute
by behavior therapy. Behavior Research \& Therapy, 1966, 4, 141.

Gordon, A., \& Baum, M. Increased efficacy of flooding (response prevention) in rats through positive intracranial stimulation. Journal of Comparative \& Physiological Psychology, 1971, 75, 68-72.

Heise, G., \& Boff, E. Continuous avoidance as a baseline for measuring behavioral effects of drugs. Psychopharmacologia, 1962, 3, 264-282.

Kamano, D. K. Joint effect of amobarbitol and response prevention on avoidance Psychological Reports, 1968, 22, 144-546.

Kamano, D. K. Using drugs to modify the effect of response prevention on avoidance extinction. Behavior Research and Therapy, 1972, 10, 367-370. 
Kirk, R. E. Experimental design: Procedures for the behavioral sciences. Belmont, California: Brooks/Cole, 1968.

Kraft, $T$. The use of methohexitone sodium in behavioral therapy. Behavior Research \& Therapy, 1967, 5, 257.

Nelson, F. Effects of chlorp ormazine on fear extinction. Journal of Comparative \& Physiological Psychology, 1967, 64, 496-498.

Richelle, M., Xhenseval, B., Fontaine, O., \& Thone, L. Action of CDP on two types of temporal conditioning in rats. In $P$. Thompson, R. Pickens, and R. Meisch (Eds.), Readings in behavioral pharmacology. New York: Appleton-Century-Crofts, 1970, Pp. 495-506.

Stampfl, T. G., \& Levis, D. J. Implosive therapy-a behavioral therapy? Behavior R esearch \& Therapy, 1968, 6, 31-36.
Stein, L. Reciprocal action of reward and punishment mechanisms. In R. G. Heath (Ed.), The role of pleasure in behavior. New York: Hoeber, 1964. Pp. 124-125.

Wolpe, J. Psychotherapy by reciprocal inhibition. Stanford: Stanford University Press, 1958.

\section{NOTE}

1. Hogan, R. A. Research thoughts toward a computerized therapy. Unpublished, undated mimeograph.

(R eceived for publication June 25, 1974; revision received August $6,1974$. ) 